\title{
Modeling Electrochemical Behavior and Interfacial Junction Profiles of Bipolar Membranes at Solar Flux Relevant Operating Current Densities
}

\author{
Meng Lin ${ }^{a}$, Ibadillah A. Digdaya ${ }^{b}$, Chengxiang Xiang ${ }^{b^{*}}$ \\ a Department of Mechanical and Energy Engineering, Southern University of Science \\ and Technology, Shenzhen 518055, China
}

${ }^{b}$ Liquid Sunlight Alliance, and Division of Engineering and Applied Science, California Institute of Technology, Pasadena, California 91125, United States 
*To whom correspondence should be addressed: cxx@,caltech.edu, linm@sustech.edu.cn

Table S1. Diffusion coefficients of each species in aqueous solution.

\begin{tabular}{|c|c|}
\hline Species & Diffusion coefficient \\
\hline $\mathrm{H}^{+1}$ & $9.31 \times 10^{-5} \mathrm{~cm}^{2} \mathrm{~s}^{-1}$ \\
\hline $\mathrm{OH}^{-1}$ & $5.26 \times 10^{-5} \mathrm{~cm}^{2} \mathrm{~s}^{-1}$ \\
\hline $\mathrm{K}^{+1}$ & $1.95 \times 10^{-5} \mathrm{~cm}^{2} \mathrm{~s}^{-1}$ \\
\hline $\mathrm{HPO}_{4}{ }^{2-2}$ & $0.7 \times 10^{-5} \mathrm{~cm}^{2} \mathrm{~s}^{-1}$ \\
\hline $\mathrm{H}_{2} \mathrm{PO}_{4}^{-2}$ & $0.85 \times 10^{-5} \mathrm{~cm}^{2} \mathrm{~s}^{-1}$ \\
\hline $\mathrm{SO}_{4}^{2-1}$ & $1.065 \times 10^{-5} \mathrm{~cm}^{2} \mathrm{~s}^{-1}$ \\
\hline $\mathrm{NaSO}_{4}^{-2}$ & $0.618 \times 10^{-5} \mathrm{~cm}^{2} \mathrm{~s}^{-1}$ \\
\hline $\mathrm{Cl}^{-1}$ & $2.03 \times 10^{-5} \mathrm{~cm}^{2} \mathrm{~s}^{-1}$ \\
\hline$f_{\text {water }}$ & 0.215 (fitted value) \\
\hline$f_{\text {water }}$ (buffer case) & 0.158 (fitted value) \\
\hline$\theta$ in Bruggeman model & 1.5 (default value) \\
\hline$\theta$ (buffer case) & $\begin{array}{l}\mathrm{K}^{+}, \mathrm{H}_{2} \mathrm{PO}_{4}^{-} \text {and } \mathrm{HPO}_{4}{ }^{2-} \text { were fitted } \\
\text { as } 2.1,1.0 \text { and } 1.0 \text {, and kept } 1.5 \text { for } \\
\text { all other species }\end{array}$ \\
\hline
\end{tabular}


Table S2 Parameters used for calculation of dielectric constant. ${ }^{3}$

\begin{tabular}{|c|c|}
\hline Parameters & Values/Equations \\
\hline Vacuum permittivity $\left(\varepsilon_{0}\right)$ & $8.85 \mathrm{e} \times 10^{-12}(\mathrm{~F} / \mathrm{m})$ \\
\hline Water permittivity $\left(\varepsilon_{\text {water }}\right)$ & $\varepsilon_{\text {water }}=\left(2.313 \times 10^{-2}-3.475 \times 10^{-5} T\right)^{-1} \varepsilon_{0}$ \\
\hline Membrane permittivity $\left(\varepsilon_{\text {mem }}\right)$ & $\varepsilon_{\text {mem }}=2.21 \varepsilon_{0}$ \\
\hline Fitting permittivity $\left(\varepsilon_{\text {fit }}\right)$ & $\varepsilon_{\text {fit }}=\varepsilon_{0}\left(0.48+4.55 f_{\text {water }}\right) /\left(0.27 f_{\text {water }}-2.39\right) /((1-$ \\
$\left.\left.f_{\text {water }}\right) f_{\text {water }}\right)^{3}$
\end{tabular}

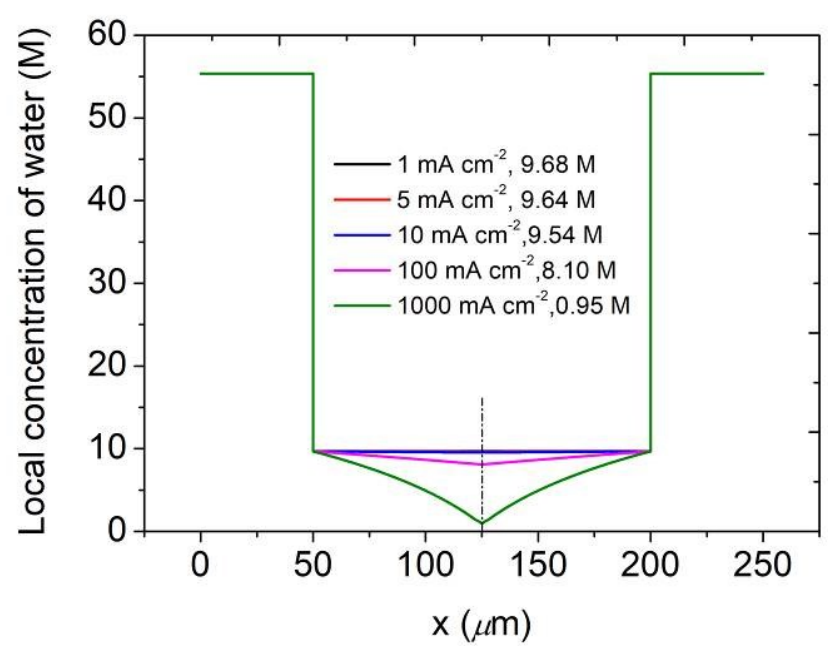

Figure S1. Local water concentration profiles and junction concentration values as a function of operational current density. 


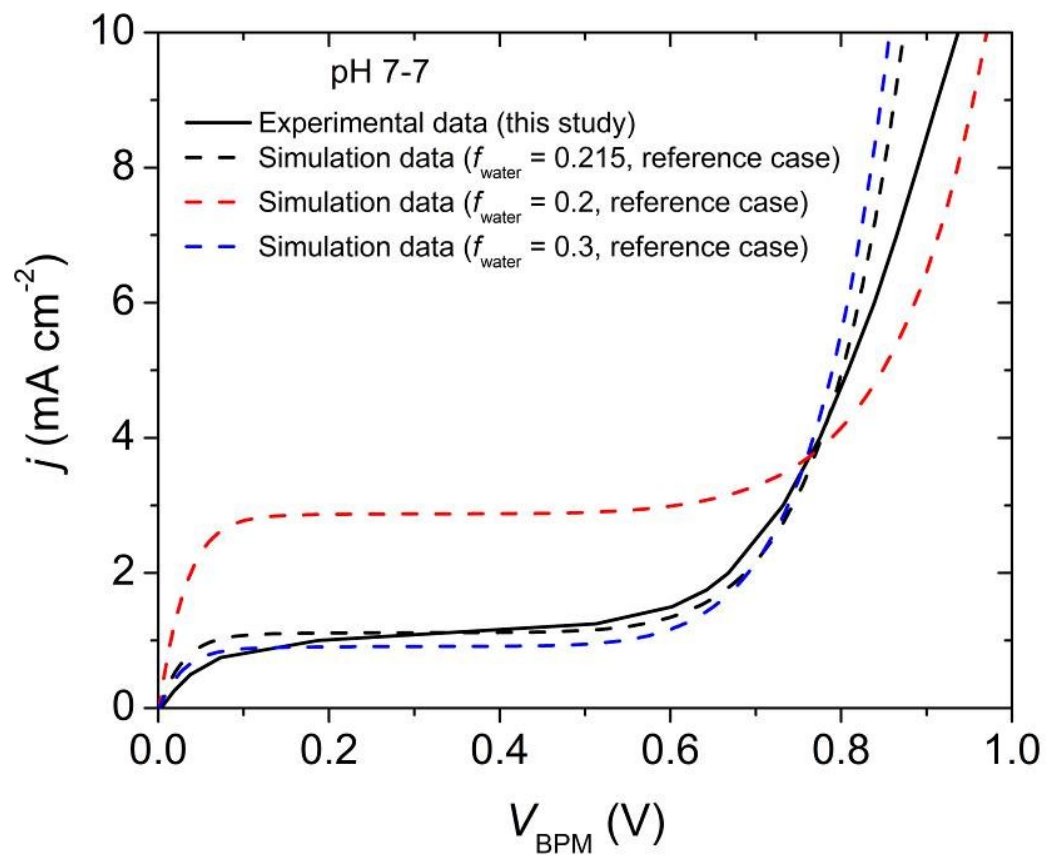

Figure S2. The IV curves for the cases with different water fractions.

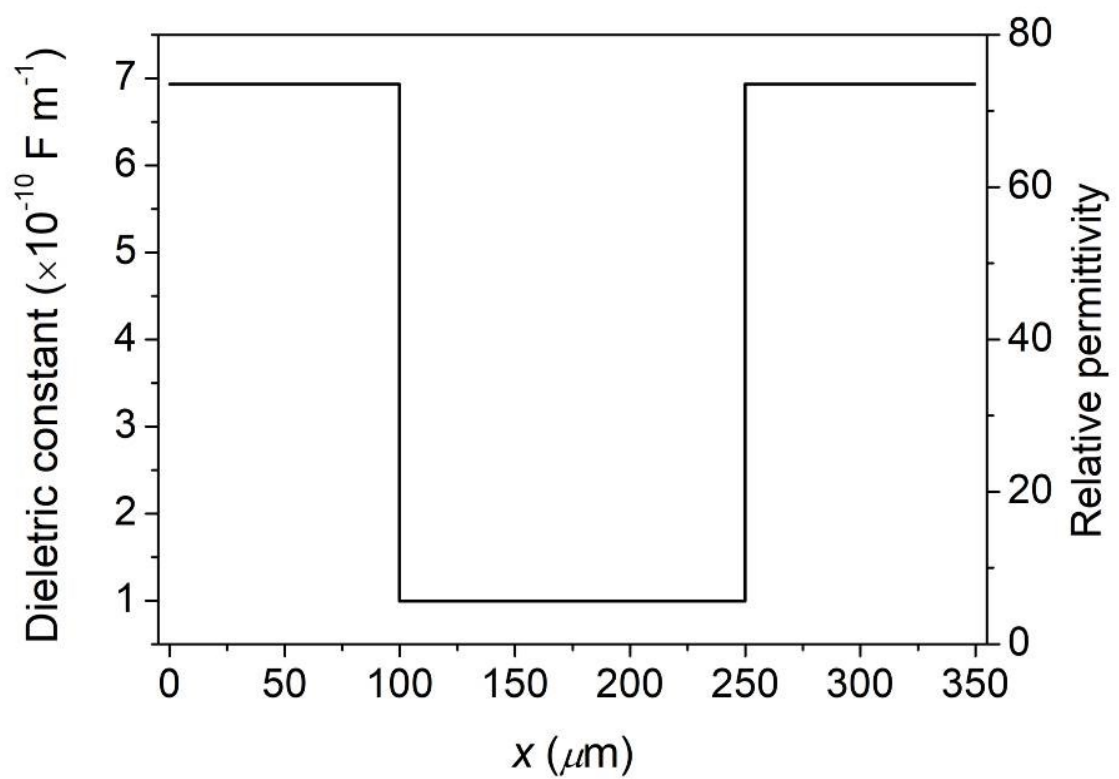

Figure S3. Dielectric constant and relative permittivity along $x$ axis. 
Table S3. Summary of governing equations. The total number of governing PDEs are 10 for $\mathrm{pH} 0 / \mathrm{pH} 14$ case, 12 for $\mathrm{pH} 7 / \mathrm{pH} 7$ case, and 16 for phosphate buffer case.

\section{Nernst-Planck equations:}

pH 0/pH 14 case: $i=\mathrm{H}_{3} \mathrm{O}^{+}, \mathrm{OH}^{-}, \mathrm{K}^{+}$, and $\mathrm{Cl}^{-}$;

pH 7/pH 7 case: $i=\mathrm{H}_{3} \mathrm{O}^{+}, \mathrm{OH}^{-}, \mathrm{K}^{+}, \mathrm{SO}_{4}^{2-}$, and $\mathrm{NaSO}^{-}$;

phosphate buffer case: $i=\mathrm{H}_{3} \mathrm{O}^{+}, \mathrm{OH}^{-}, \mathrm{K}^{+}, \mathrm{HPO}_{2}^{-}, \mathrm{H}_{2} \mathrm{PO}_{4}^{-}, \mathrm{NaHPO}_{4}^{-}$, and $\mathrm{NaH}_{2} \mathrm{PO}_{4}$

$N_{i}=-D_{i} \frac{d c_{i}}{d x}+n D_{i} c_{i} \frac{F E}{R T}+D_{i} c_{i} \frac{d c_{H_{2} O}}{d x}+0.5 D_{i} c_{i} \frac{d \ln \left(\frac{k_{-}^{E}}{k_{+}^{E}}\right)}{d x}\left(i=H_{3} O^{+}, O H^{-}\right)$

$N_{i}=-D_{i} \frac{d c_{i}}{d x}+n D_{i} c_{i} \frac{F E}{R T}+D_{i} c_{i} \frac{d c_{H_{2} O}}{d x} \quad\left(i \neq H_{3} O^{+}, O H^{-}\right)$

$\frac{d N_{i}}{d x}=R_{i}$

(S3)

\section{Possions' equations:}

$$
\begin{gathered}
\frac{d(\varepsilon E)}{d x}=F \sum_{i} c_{i} \\
-\frac{d \phi}{d x}=E
\end{gathered}
$$


Table S4. Reaction constants used in this study. ${ }^{3}$

\begin{tabular}{|l|l|}
\hline Parameters & Values \\
\hline$k_{+1}^{0}{ }^{3}$ & $3.67 \times 10^{-10} \mathrm{~m}^{3} \mathrm{~s}^{-1} \mathrm{~mol}^{-1}$ \\
\hline$k_{-1}^{0}{ }^{3}$ & $1.11 \times 10^{8} \mathrm{~m}^{3} \mathrm{~s}^{-1} \mathrm{~mol}^{-1}$ \\
\hline$k_{+2}^{0}{ }^{3}$ & $83.9 \mathrm{~m}^{3} \mathrm{~s}^{-1} \mathrm{~mol}^{-1}$ \\
\hline$k_{-2}^{0}{ }^{3}$ & $2.13 \times 10^{7} \mathrm{~m}^{3} \mathrm{~s}^{-1} \mathrm{~mol}^{-1}$ \\
\hline$k_{+3}^{0}{ }^{3}$ & $1.8 \times 10^{5} \mathrm{~m}^{3} \mathrm{~s}^{-1} \mathrm{~mol}^{-1}$ \\
\hline$k_{-3}^{0}{ }^{3}$ & $2.15 \times 10^{7} \mathrm{~m}^{3} \mathrm{~s}^{-1} \mathrm{~mol}^{-1}$ \\
\hline pKa for R4 ${ }^{5}$ & 6.62 at $1.0 \mathrm{M}^{-1}$ \\
\hline$k_{+4}$ & $10^{2} \mathrm{~s}^{-1}$ \\
\hline$K_{5}{ }^{6}$ & $0.483 \mathrm{M}$ \\
\hline$k_{5+}$ & $10^{2} \mathrm{~s}^{-1}$ \\
\hline
\end{tabular}




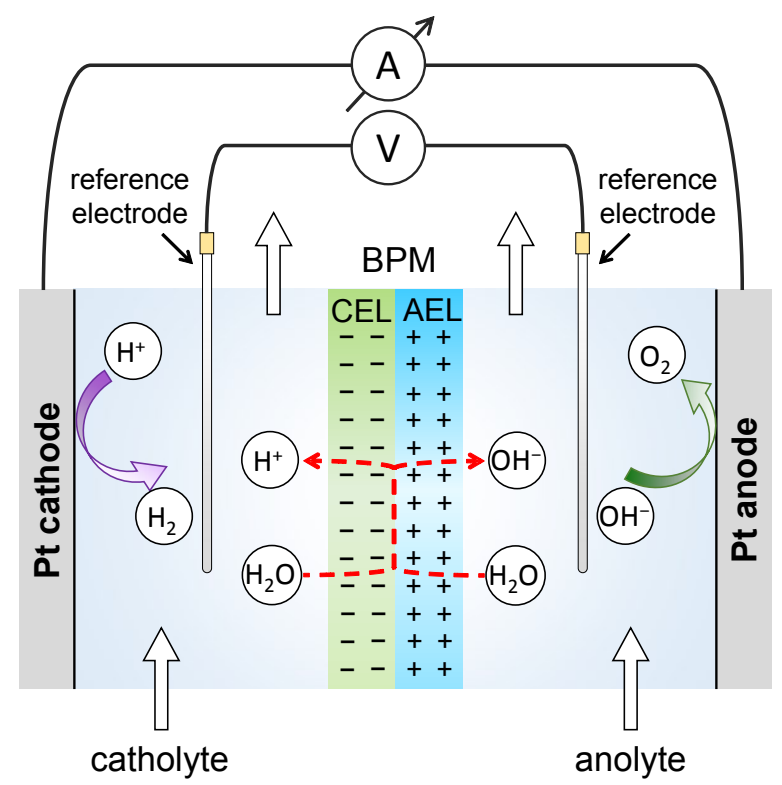

Figure S4. Schematic illustration of the experimental setup consisting of a Pt cathode, a catholyte compartment, a BPM, an anolyte compartment and a Pt anode. BPM voltages were measured in a 4-wire sensing mode. Electrical currents were applied at the cathode and at the anode, and the voltage differences between the two reference electrodes were measured. 

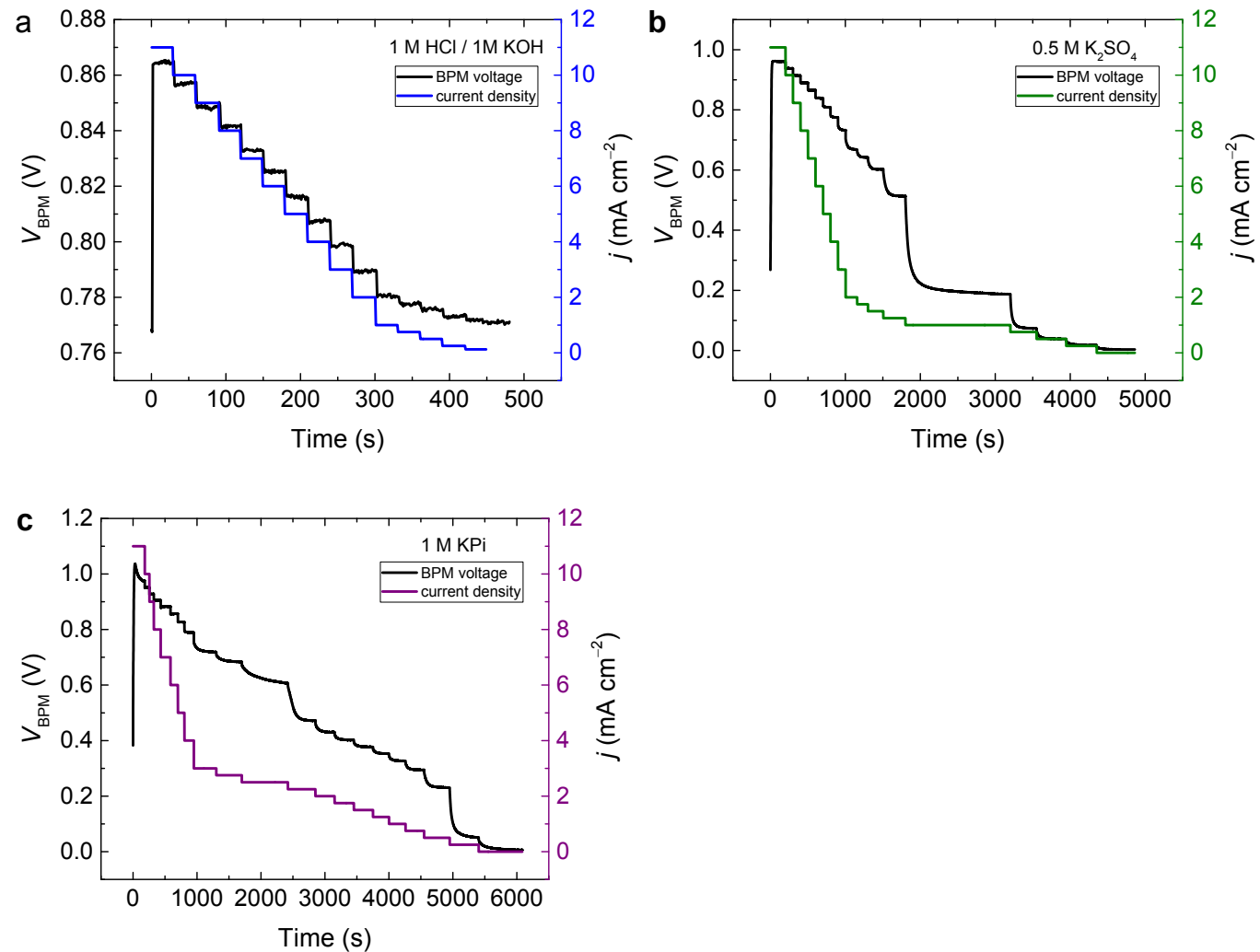

Figure S5. BPM voltage measurements using multistep chronopotentiometry mode from high current density $\left(11 \mathrm{~mA} \mathrm{~cm}{ }^{-2}\right)$ to low current density $\left(0 \mathrm{~mA} \mathrm{~cm}{ }^{-2}\right)$ for (a) 1 $\mathrm{M} \mathrm{HCl}$ and $1 \mathrm{KOH}$ (pH 0/pH 14), (b) $0.5 \mathrm{M} \mathrm{K}_{2} \mathrm{SO}_{4}$, and (c) $1 \mathrm{M}$ potassium phosphate buffer (containing $0.54 \mathrm{M} \mathrm{K}_{2} \mathrm{HPO}_{4}$ and $0.46 \mathrm{KH}_{2} \mathrm{PO}_{4}$ ). The voltage at each applied current density was recorded once the voltage stabilized to ensure that the BPM voltage was not underestimated. 


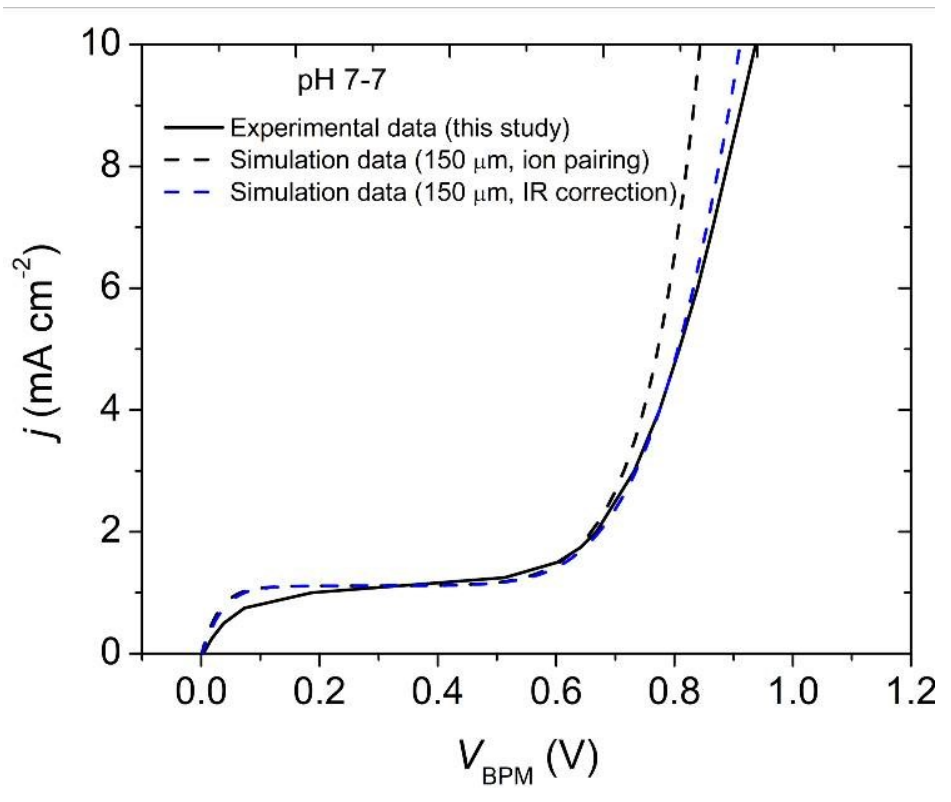

Figure S6. IR corrected IV curve for the $\mathrm{pH} 7 / \mathrm{pH} 7$ case.

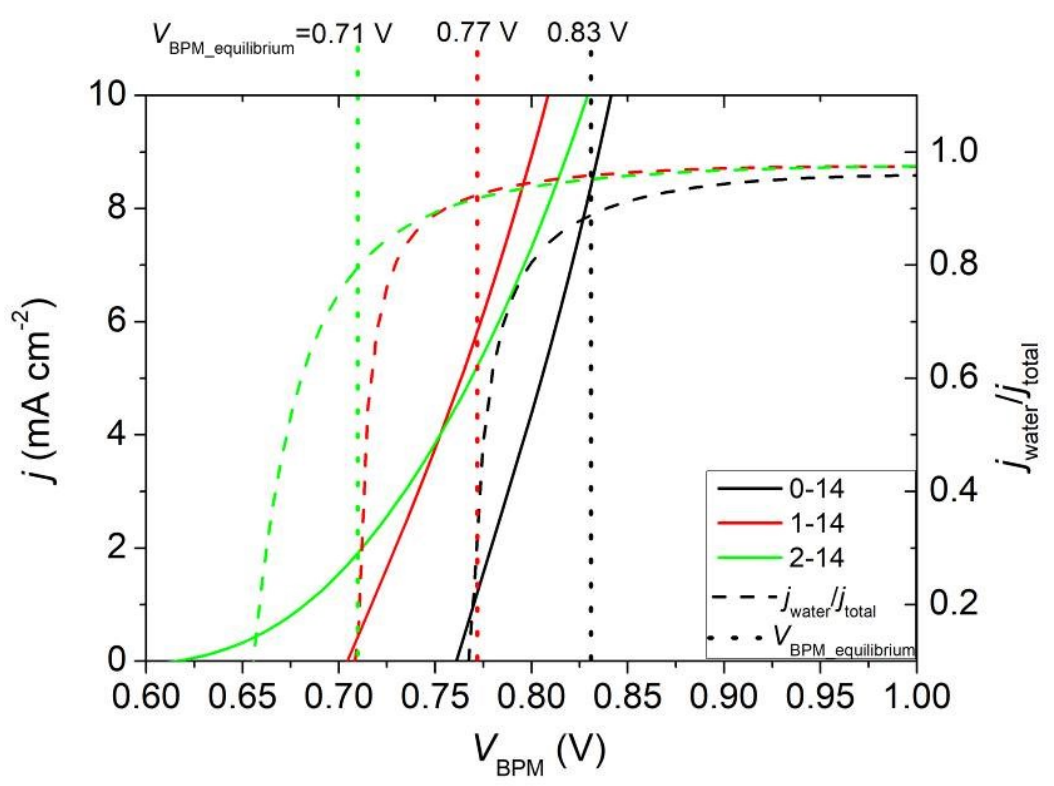

Figure S7. The total current density (left y-axis, solid lines) and fraction of current density due to water dissociation (right y-axis, dashed lines) for different combination of $\mathrm{pHs}(0-14,1-14,2-14)$. The equilibrium potentials are indicated by colored dots. The pHs at the two sides of BPM are created numerically by changing the concentration of $\mathrm{HCl}$ (CEM side) and $\mathrm{KOH}$ (AEM side). This verifies the water dissociation has been activated before the equilibrium potential. 


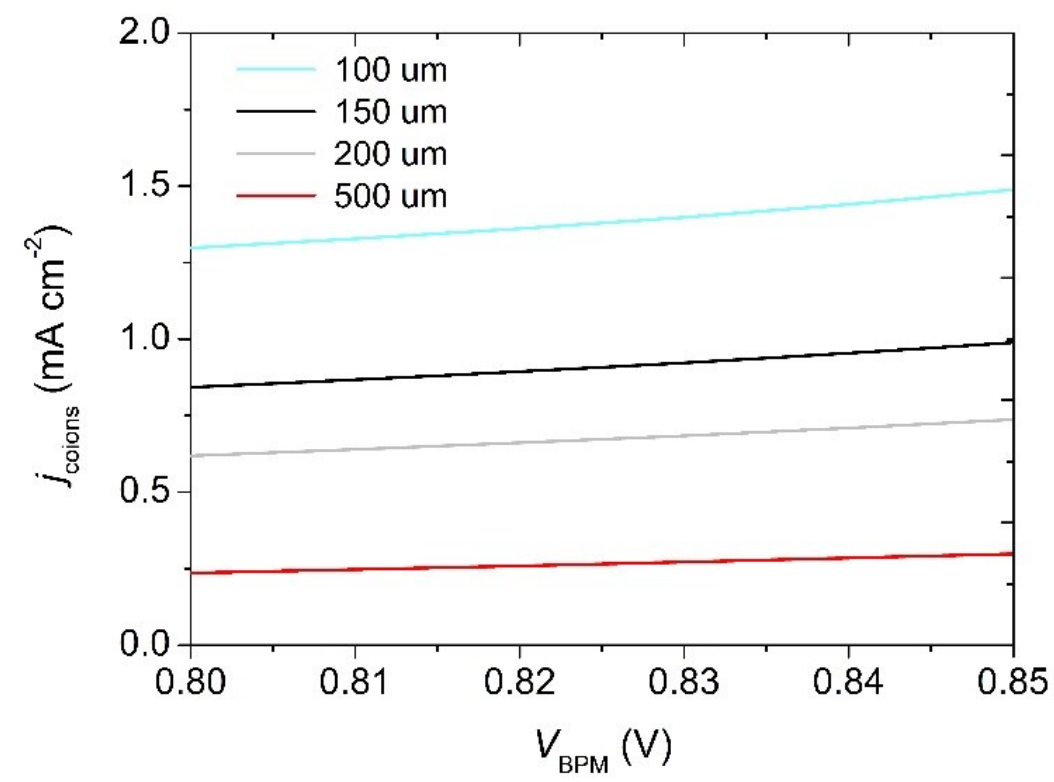

Figure $\mathrm{S} 8$. Co-ion partial current density as a function of $\mathrm{V}_{\mathrm{BPM}}$ for various membrane thickness.

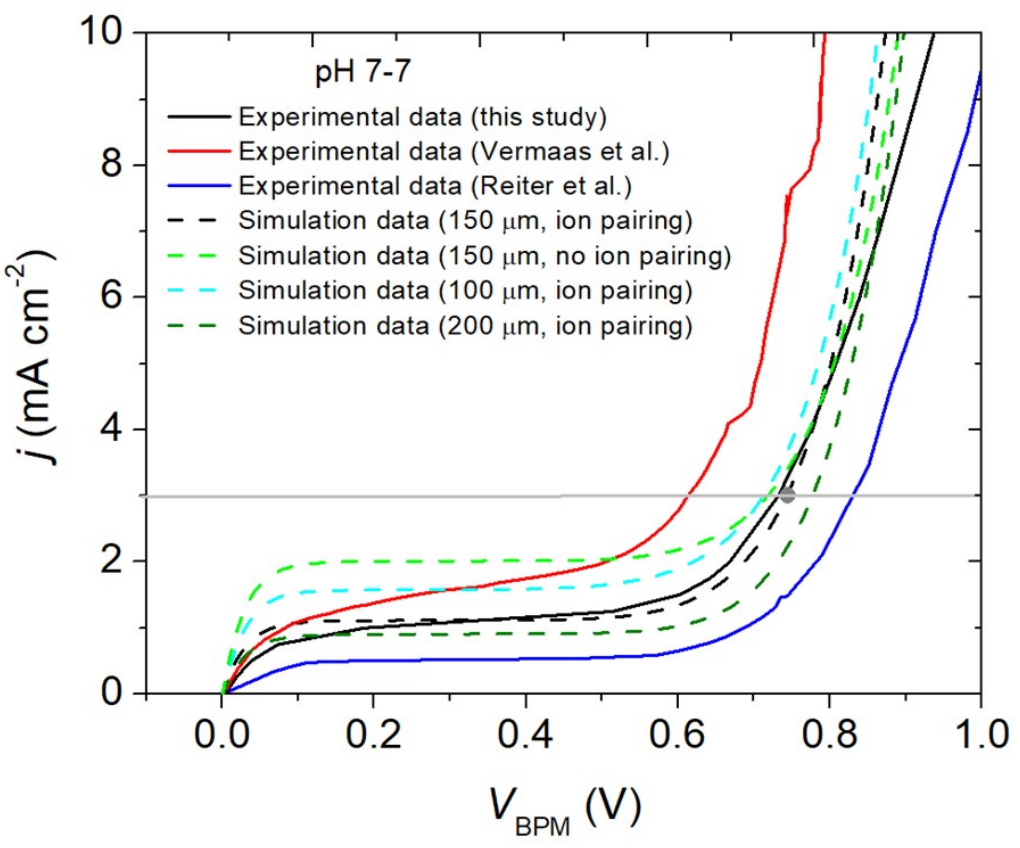

Figure S9. Effect of membrane thickness on the electrochemical behavior of the BPM. Note that the AEL and CEL are assumed to identical in thickness. 

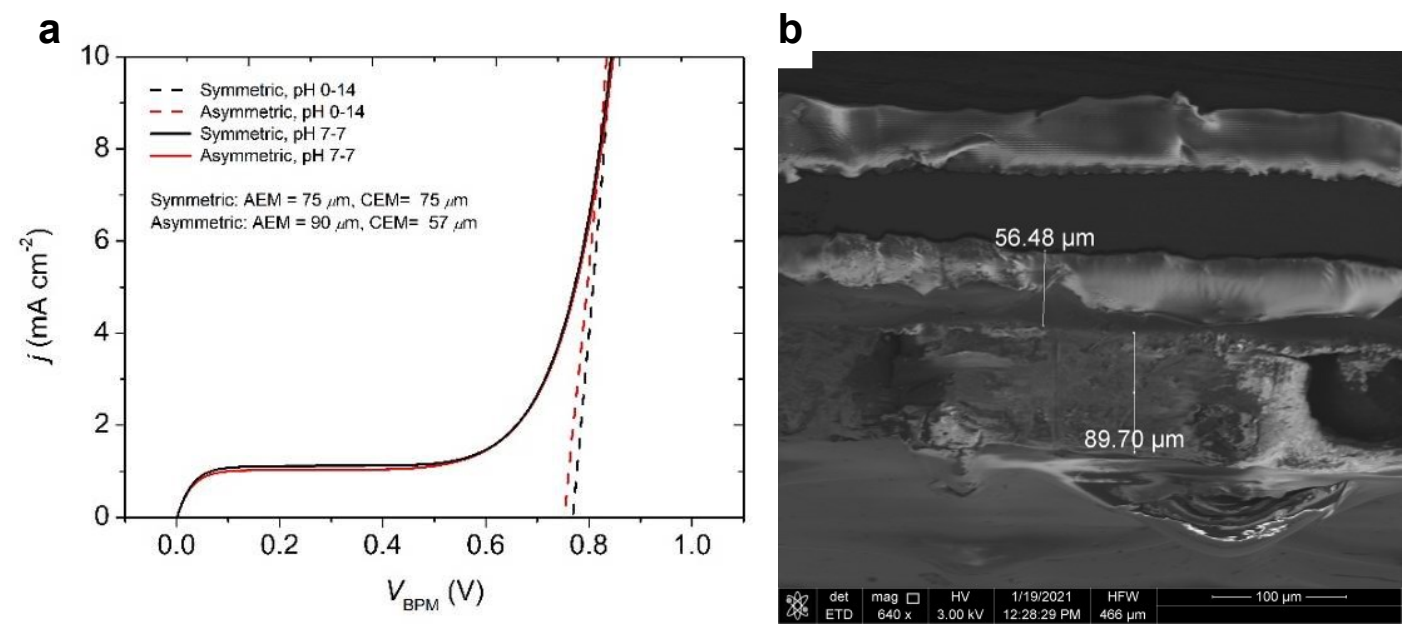

Figure S10: (a) Effect of asymmetric membrane thickness on the electrochemical behavior of BPM for both $0-14$ and 7-7 cases. The asymmetric dimensions are obtained experimentally. (b) Cross-section scanning electron microscopy (SEM) image of the Fumasep BPM, showing asymmetric thickness of anion exchange layer $(89.7 \mu \mathrm{m})$ and cation exchange layer $(56.48 \mu \mathrm{m})$

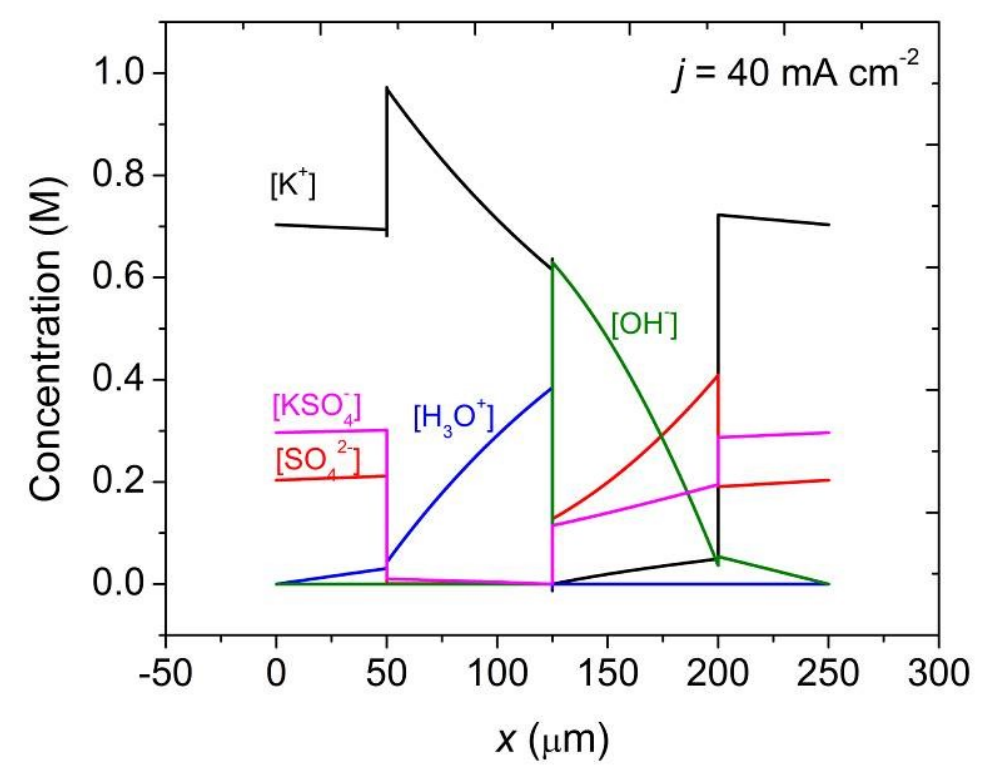

Figure $\mathrm{S} 11$. The concentration profile of $\mathrm{H}_{3} \mathrm{O}^{+}, \mathrm{OH}^{-}$and other co-ions across the $\mathrm{BPM}$ at different $\mathrm{pKa}$ of the WD catalyst at a current density of $40 \mathrm{~mA} \mathrm{~cm}^{-2}$. 


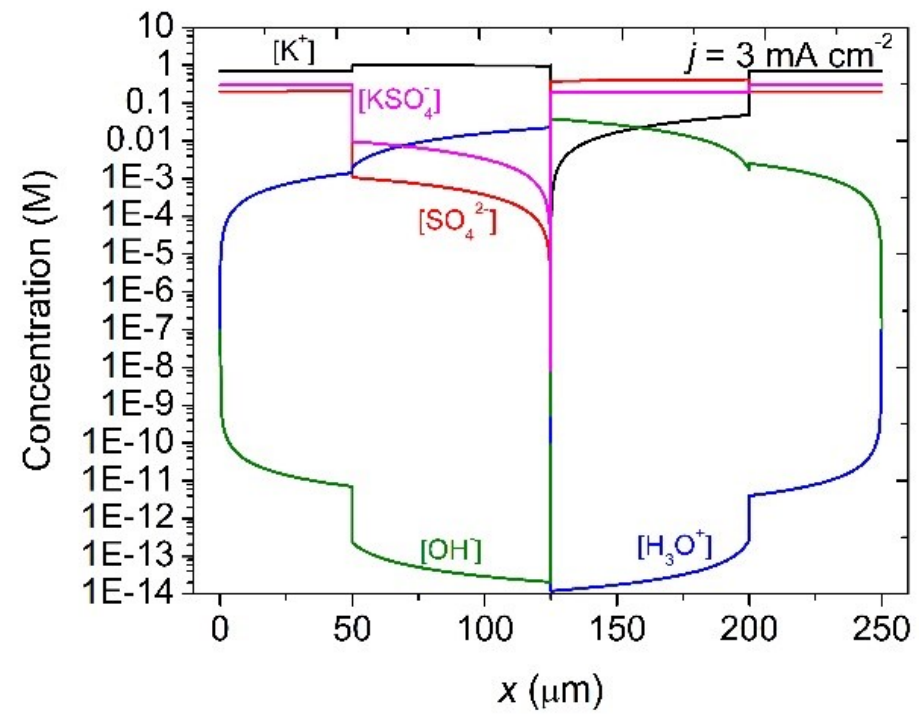

Figure $\mathrm{S} 12$. The concentration profile of $\mathrm{H}_{3} \mathrm{O}^{+}, \mathrm{OH}^{-}$and other co-ions across the BPM at a current density of $3 \mathrm{~mA} \mathrm{~cm}^{-2}$.

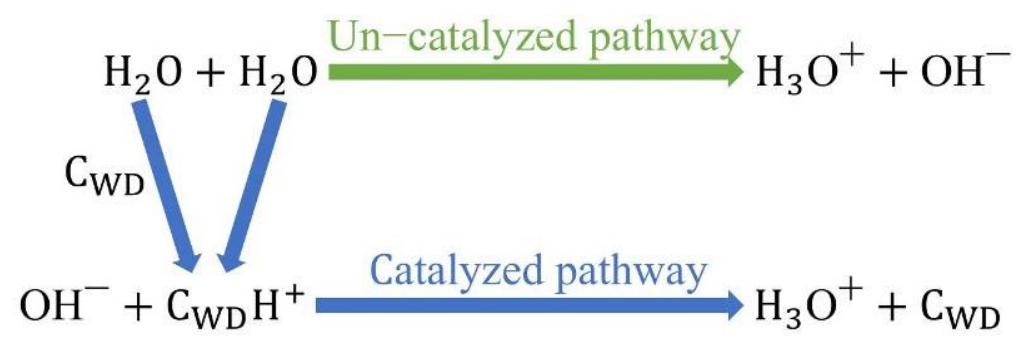

Figure S13. Schematic for the catalyzed and uncatalyzed pathways for water dissociation reactions at CL. 


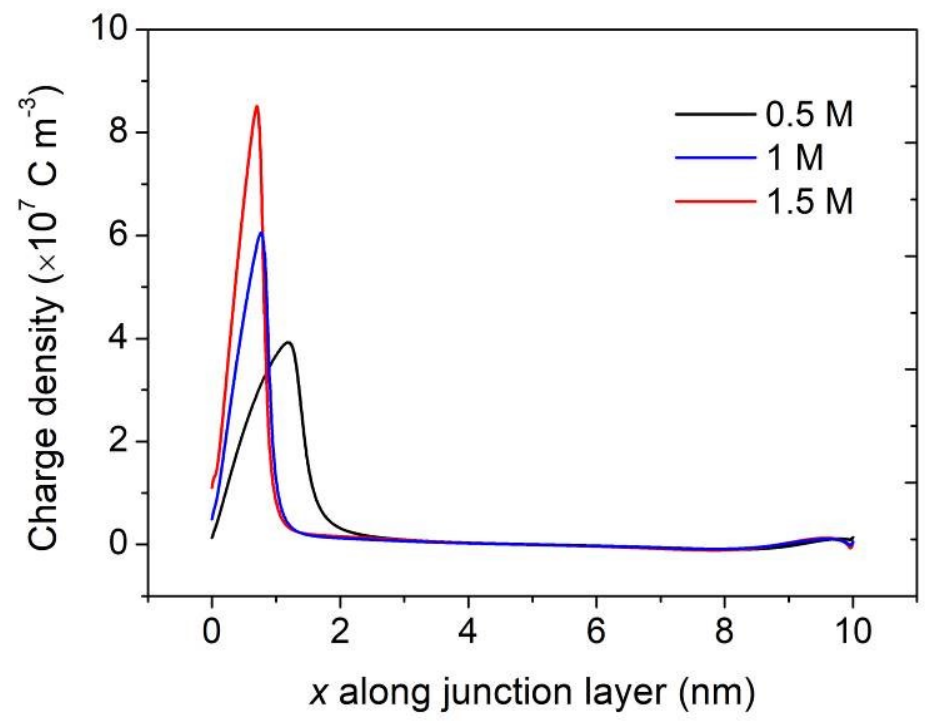

Figure S14. Charge density along the BPM junction layer for different fixed charge densities.

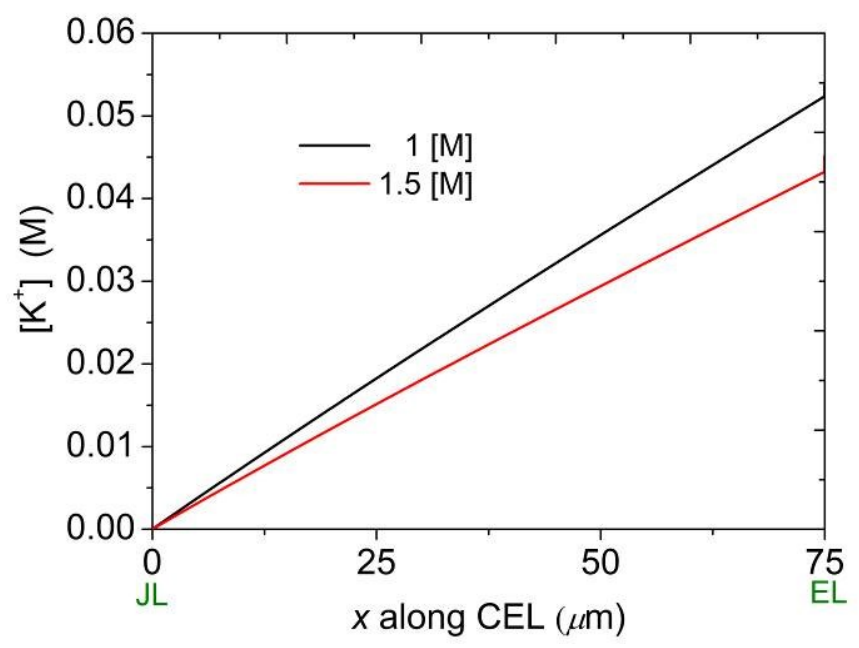

Figure $\mathrm{S} 15$. The $\mathrm{K}^{+}$concentration at CEL under different fix charge density at a current density of $3 \mathrm{~mA} \mathrm{~cm}-2$. 

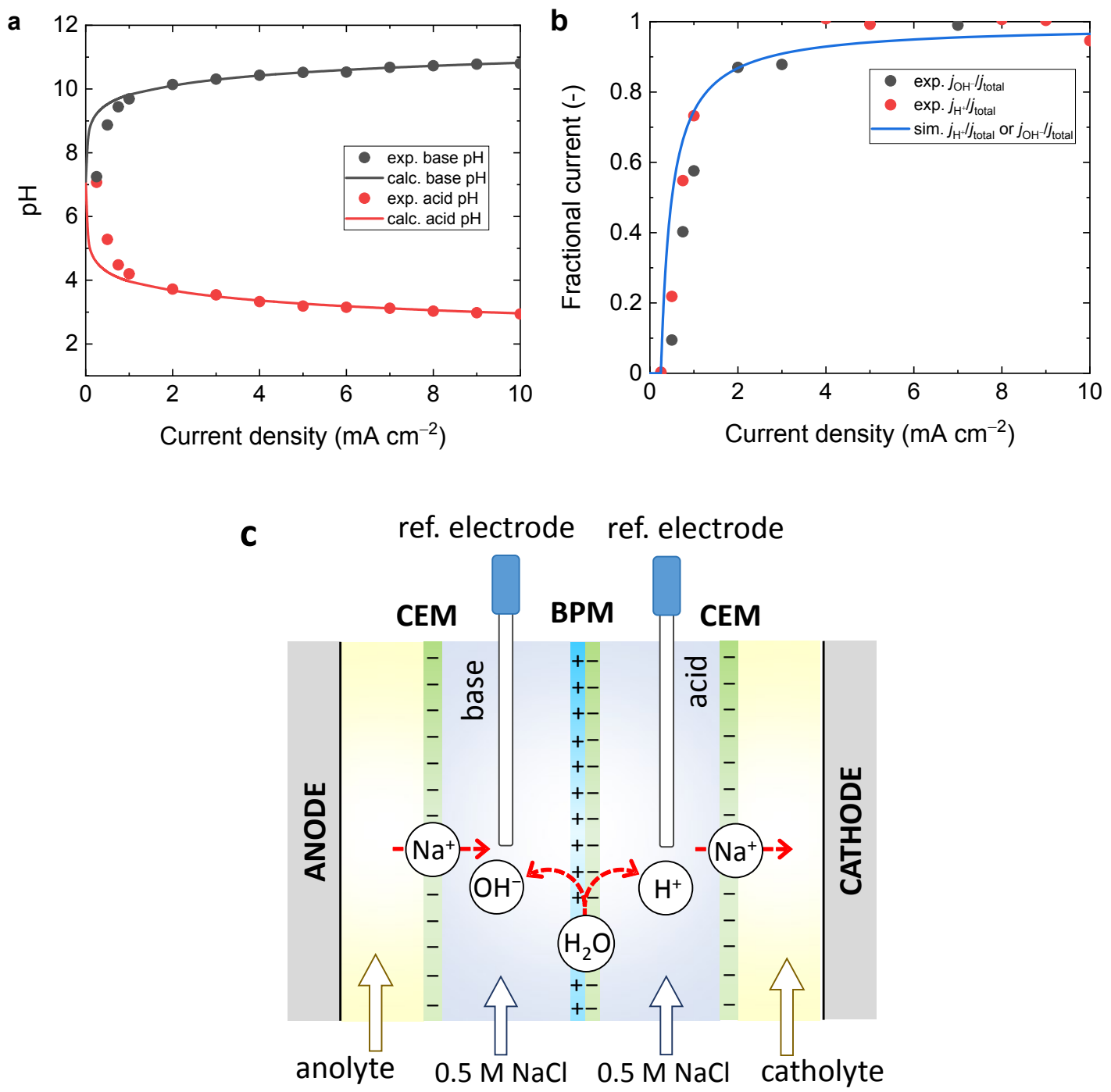

Figure S16. (a) The experimental (exp.) and calculated (calc.) acid and base $\mathrm{pH}$ as a function current density for a $0.5 \mathrm{M} \mathrm{NaCl}$ solution and a BPM with an active area of $0.95 \mathrm{~cm}^{2}$. Calculated values assumed $100 \%$ generation rate of protons and hydroxides $\left(G_{\mathrm{H}^{+}}, G_{\mathrm{OH}^{-}}=I /(n F)\right.$, where $I$ is the absolute current, $n$ is the number of participating electron (1) and $F$ is the Faraday's constant) at the BPM. The experimental data were determined from $\mathrm{pH}$ measurements of the output solutions. (b) Experimental and simulated (sim.) values of partial current density carried by $\mathrm{H}^{+}$and $\mathrm{OH}^{-}$as a function of the total current density. Experimental data were determined by dividing the generated $\mathrm{H}^{+}$and $\mathrm{OH}^{-}$as measured from the solutions $\mathrm{pH}$ with the calculated values assuming $100 \%$ generation of protons and hydroxides at the BPM. The low fractional current of $\mathrm{H}^{+}$and $\mathrm{OH}^{-}$at low current densities represent the co-ion leakage $\left(\mathrm{Na}^{+}\right.$and $\mathrm{Cl}^{-}$) due to imperfect permselectivity of the anion exchange layer (AEL) and cation exchange layer (CEL) of the BPM. (c) Experimental electrochemical setup for the $\mathrm{pH}$ measurements, consisting of (left to right) an anode, an anolyte compartment, an CEM, a base compartment, a BPM, an acid compartment, a CEM, a catholyte and a cathode. The anolyte and catholyte were $1 \mathrm{M} \mathrm{Na}_{2} \mathrm{SO}_{4}$ and the investigated solution flowing through the base and acid compartment was $0.5 \mathrm{M} \mathrm{NaCl}$. The concentration 
of $\mathrm{Na}^{+}$in the acid compartment was significantly higher $(0.5 \mathrm{M})$ than that of $\mathrm{H}^{+}$ generated at the BPM (between $10^{-7}$ and $10^{-3}$ for $\mathrm{pH} 7$ to $\mathrm{pH} 3$ ), and therefore the transference number was close to unity for $\mathrm{Na}^{+}$across the CEM, and the transport of $\mathrm{H}^{+}$escaping from the acid compartment to the catholyte compartment was negligible.

\section{References:}

1 J. Newman and K. E. Thomas-Alyea, Electrochemical Systems, 3rd Edition, 2004.

2 D. L. Parkhurst and C. A. J. Appelo, Model. Tech. B. 6, , DOI:Rep. 99-4259.

3 N. Craig, UC Berkeley Electron. Theses Diss., 2013, 116.

4 F. E. Critchfield, J. A. Gibson and J. L. Hall, J. Am. Chem. Soc., 1953.

5 A. A. Green, J. Am. Chem. Soc., 1933, 55, 2331-2336.

6 E. J. Reardon, J. Phys. Chem., 1975, 79, 422-425. 